\title{
Subjects' expectations, individual variability, and the scanning of mental images
}

\author{
DAVID B. GOLDSTON and JAMES V. HINRICHS \\ University of Iowa, Iowa City, lowa \\ and \\ CHARLES L. RICHMAN \\ Wake Forest University, Winston-Salem, North Carolina
}

\begin{abstract}
The near-perfect correlation between mental imagery scanning times (averaged across subjects) and interobject distances on imaged maps has been cited as evidence for Kosslyn's (1981) analog theory of mental imagery. Present results (1) indicate that individual subjects' scanning-time/distance correlations vary as a function of instructional set (and, hence, a priori expectations), and (2) reveal a large degree of individual variability in scanning-time/distance correlations.
\end{abstract}

Kosslyn, Ball, and Reiser (1978) found that scanning times between objects on a mental image of a map (averaged across subjects) correlated +.97 with interobject distances on the original map. From this high correlation, Kosslyn et al. inferred that the distances between different objects in the viewing field were relatively preserved in the images (analog representations) of that field (Kosslyn, 1981; Kosslyn et al., 1978; Kosslyn, Pinker, Smith, and Shwartz, 1979). Unfortunately, the scanning-time/distance correlations for individual subjects were not reported. This absence of data was regrettable, given Kosslyn, Brunn, Cave, and Wallach's (1984) recent demonstration of large individual differences in imagery tasks other than scanning tasks. Because the analog model purports to describe a perception-like process occurring within individuals, the first goal of the present study was to investigate individual subjects' scanning-time/distance correlations.

As suggested by Finke and Shepard (in press), the second goal of the present study was to investigate an alternative determinant of mental imagery scanning results. Pylyshyn (1981) argued that the imagery-scanning task was "cognitively penetrable" (p. 21) (i.e., a task in which performance varies in a rationally explicable manner with subjects' beliefs, expectations, knowledge, or goals). According to Kosslyn (1981), "cognitive penetration is important insofar as it demonstrates that properties of struc-

This research was supported in part by funds from the National Institute of Mental Health, PHS, MH36491, and the Wake Forest University Research and Publication Fund to Charles L. Richman. This experiment was reported at the annual meeting of the Midwestern Psychological Association, Chicago, IL, April, 1984. We thank Melanie Payne, Donald Routh, Harriet Shaklee, and the reviewers for their constructive criticisms of earlier drafts of this paper. We are also indebted to Dee Norton for his invaluable statistical guidance. Requests for reprints should be sent to David B. Goldston, Department of Psychology, The University of lowa, lowa City, IA 52242. tures or processes are not fixed. We have claimed that the properties of the visual buffer are innately determined and they should not be subject to cognitive penetration" (p. 56). Because the analog theory cannot account for the possible effects of beliefs and expectations without the hypothesis of extra variables (and hence, extra degrees of freedom which negate the theory's predictive power), cognitive penetrability is a viable challenge to the notion that only perception-like processes are tapped in mental imagery tasks (Pylyshyn, 1981).

Richman, Mitchell, and Reznick (1979) and Mitchell and Richman (1980) demonstrated that scanning times per se were cognitively penetrable by both semantic and tacit knowledge. In their studies, (1) subjects' scanning times varied with different verbal distance cues (distances on signposts) regardless of physical distance between objects, and (2) subjects were able to predict a linear relationship between scanning time and physical distance when acquainted with the procedure of imagery-scanning experiments. Intons-Peterson (1983) also found subjects' scanning times to be cognitively penetrable, but in her study, scanning times varied with experimenters' expectations instead of subjects' expectations. When experimenters were given different expectations for subjects' performance, the scanning times elicited from subjects corroborated these different expectations. In contrast, Jolicoeur and Kosslyn (1985) found that experimenters with different expectations did not elicit scanning-time/distance correlations which significantly departed from linearity. Finally, Goldston and Richman (1982) replicated the Kosslyn et al. (1978) group results $(\mathrm{r}=+.93$ ), but also demonstrated that subjects' scanning-time/distance correlations varied with social desirability and post hoc self-ratings of expectations. ${ }^{1}$

The results of these studies are suggestive but not conclusive. Because the Goldston and Richman (1982) study was correlational, the question remained of whether be- 
liefs actually affected the scanning-time/distance relationship or whether experience with the scanning task affected the later self-report of beliefs. The results of Jolicoeur and Kosslyn (1985) were not compelling because they represent a failure to reject the null hypothesis. Predictions by subjects of scanning times in the Richman et al. (1979) and Mitchell and Richman (1980) studies did not necessarily require the scanning of mental images. Both the Richman et al. (1979) signpost study and the IntonsPeterson (1983) studies used maps simpler than those used by Kosslyn et al. (1978), and more important, the two more recent studies measured the effects of expectations on scanning times per se, rather than on the scanningtime/distance relationship. The analog model makes no predictions about whether specific scanning times will be long or short; the model simply predicts that the time to scan longer imaginal distances will be longer relative to the time to scan shorter imaginal distances (Jolicoeur \& Kosslyn, 1985). Furthermore, the most straightforward evidence for cognitive penetrability would appear to be provided by direct manipulation of subjects' expectations rather than indirect manipulations of experimenters' beliefs.

Therefore, the present experiment was designed to manipulate a priori expectations and assess their effects on individual subjects' scanning-time/distance correlations and their later memory for the map. Subjects' expectations were manipulated via the initial instructions. With the exception of one paragraph in each subject's instructions, the scanning task was identical for all subjects. In the different groups, subjects were told (1) to expect a positive relationship, (2) to expect a negative relationship, (3) to expect no relationship between scanning time and distance, or (4) that the experimenters had no expectations for their performances.

We anticipated that the positive-expectation subjects would generate scanning results similar to those obtained by Kosslyn et al. (1978), because the natural intuition is that it takes longer to travel across distances which are further apart. The rationale for the negative-expectation group was inspired by the subjects in the Kosslyn et al. (1978) experiment who complained that it was harder to scan the smaller distances between locations on the map which were "cluttered together." The zero-expectation group's rationale implied rapid scanning across "miniscule" distances, and was important given the Kerr and Neisser (1983) finding that some imagery results (e.g., better recall for concealed than separate images) dissipate when subjects respond quickly. The results of the noexpectation group were important given the IntonsPeterson (1983) finding that subjects tend to adjust their scanning times to what they perceive to be the expectations of the experimenter for their performance.

\section{METHOD}

\section{Subjects}

Seventy-two male University of Iowa introductory psychology students served as subjects in exchange for research participation credit. Subjects were tested individually and were assigned to the conditions in a pseudorandom fashion. (A block comprising assignments to each of the four conditions was filled before a subject could be assigned to the next block.) The four groups were comparable in Marlowe-Crowne (Crowne \& Marlowe, 1960) social desirability scores $[\mathrm{F}(3,68)<1.00]$.

\section{Materials}

Subjects memorized and scanned the map of a fictional island used by Kosslyn et al. (1978). On this map were seven objects: a hut, a well, a tree, a lake, a rock, grass, and sand. A small red dot marked the location of each object; beside each dot was a small picture of the appropriate object. The map was reconstructed from the illustration (p. 51) of Kosslyn et al.'s original article with the constraint that each of the 21 distances between objects (dots) had to be at least $.5 \mathrm{~cm}$ longer than the next shortest distance.

The tape recording used in the scanning task consisted of 42 pairs of words. Each possible pair of locations was presented twice, with the order of the pair alternating. The ordering of pairs was random with the exception that no object could occur twice within three adjacent pairs (e.g., hut-rock, sand-tree, well-lake, grass-hut, rocktree, etc.).

\section{Procedure}

The subject was seated in a small (approximately $1.8 \times 1.2 \mathrm{~m}$ ) acoustic isolation chamber facing a blank wall; in front of the subject was a table containing a switch and a tape recorder. The subject listened to a brief description of the scanning task which informed the subject that we were "collecting baseline compatison data for a visual perception experiment. In that experiment, we will monitor eye movements while people scan pictures."

In the positive-expectation group, subjects were told that:

The time to scan between objects in that experiment as well as with the mental map in this study will increase as the distances between the objects get longer; in other words, the farther apart two objects are, the longer it will take to scan the distances between them. This is best understood if you consider that it simply takes longer to travel between two places that are farther apart.

In the negative-expectation group, subjects were told that:

The time to scan between objects in that experiment as well as with the mental map in this study will increase as the distances between the objects get shorter. This is best understood if you consider the nature of scanning: If you are scanning longer distances (e.g., for a tower on the horizon), you cover great distances very quickly, because you do not have to worry about all the cluttered details which are close in; if scanning shorter distances (e.g., for a book in the library, or in the middle of a cluttered desk), you take much longer, because there are a lot of items and objects which you have to discriminate and attend to.

In the zero-expectation group, subjects were told that:

All of the scanning times in both that experiment, and with the mental map in this study will be approximately equal. This is best understood if you consider that distances between objects as represented on a mental image in your head would have to be miniscule, and for all practical purposes, dealt with equivalently.

In the no-expectation group, subjects were told:

We expect that the results (the scanning times) in this experiment will be comparable to those in the visual perception experiment, but we really have no other guesses as to the possible outcomes.

Subjects were then asked to practice the use of mental imagery and scanning. They were asked to form a mental image of the continental United States which contained the locations of five cities: New York, Miami, Houston, Los Angeles, and Chicago. Subjects 
heard and read a written summary of scanning instructions similar to those used by Kosslyn et al. (1978) and Jolicoeur and Kosslyn (1985). The written summaries of the scanning instructions also included statements regarding the purpose of the experiment ("baseline comparison data for a visual perception experiment"), and our expectations for their performance (without the rationale).

The practice procedure comprised six scanning trials. The cities in each pair were presented $5 \mathrm{sec}$ apart, with an intertrial interval of $3 \mathrm{sec}$. The subjects pressed a switch to stop a clock which began running concurrently with the naming of the second city. If subjects did not follow instructions or used the apparatus incorrectly, they were corrected, the tape recorder was rewound, and the subjects began again with the first pair presentation.

After the practice task, subjects were familiarized with the map of the fictional island, and they practiced reproducing the map until they could locate each of the representative dots to within $.5 \mathrm{~cm}$ of the dots' original locations. Subjects reproduced the dots on sheets of paper which contained an outline of the map. Accuracy was determined by placing over the subjects' worksheets a transparency with the outline of the map, the dots, and a dashed circle $.5 \mathrm{~cm}$ around the dots. When memorizing the map, subjects were allowed to study the original map and, after the first trial, the outline with the overlaying transparency.

After subjects reproduced the map accurately, we read to the subjects the same instructions used in the practice scanning task (with the exception of referring to "objects" instead of "cities"). While instructions were read to subjects, the subjects were encouraged to read simultaneously their written summaries of these instructions. During the subsequent scanning task, the objects within a pair were presented $5 \mathrm{sec}$ apart, with an intertrial interval of $3 \mathrm{sec}$. Following the scanning procedure, subjects were given another outline of the map and were asked to draw the locations of the objects before being debriefed.

\section{RESULTS AND DISCUSSION}

For some subjects, individual scanning times were lost due to mechanical-electrical malfunction or due to subjects' failures to press the switch. No subjects lost more than 3 of 42 scanning times through malfunction or subject error. In addition, one subject (in the negativeexpectation group) did not draw a map after the scanning task. In contrast to the Kosslyn et al (1978) procedure of eliminating subjects' "wild scores" (thereby reducing within-subject variability), all available data were used in the present analyses.

\section{Correlations Between Scanning \\ Time and Distance}

For each of the four experimental groups, the following data are presented in Table 1: the correlations between scanning times averaged across subjects and interobject distances; the mean scanning-time/distance correlations for individual subjects; the median scanning-time/distance correlations for individual subjects; the maximum and minimum correlations for individual subjects; the standard deviations of the individual correlations; and the number of positive reliable correlations (at the .05 level of significance).

Across groups, the correlations between scanning time and interobject distance on the original map ranged from -.34 to $+.93(\mathrm{df}=19)$ for individual subjects, with both mean and median correlations of +.33 . With scanning times averaged across subjects, the correlations between scanning time and distance ranged from +.58 in the negative-expectation group to +.89 in the positiveexpectation group ( $\mathrm{df}=19)$.

Scanning time (in milliseconds) varied as a function of distance in all four groups $[\mathrm{F}(20,340)=9.80$, MSe $=128,573, \mathrm{p}<.001 ; \mathrm{F}(20,340)=2.80, \mathrm{MSe}=$ $334,981, \mathrm{p}<.001 ; \mathrm{F}(20,340=3.06, \mathrm{MSe}=137,000$, $\mathrm{p}<.001$; and $\mathrm{F}(20,340)=4.44, \mathrm{MSe}=225,702, \mathrm{p}<$ .001 , in the positive-, negative-, zero-, and no-expectation groups, respectively]. Moreover, scanning times increased in a linear manner with increasing distance in all groups $[F(1,340)=155.28$, MSe $=128,573, p<.001$; $\mathrm{F}(1,340)=18.86, \mathrm{MSe}=334,981, \mathrm{p}<.001 ; \mathrm{F}(1,340)$ $=36.26, \mathrm{MSe}=137,000, \mathrm{p}<.001 ;$ and $\mathrm{F}(1,340)=$ $58.81, \mathrm{MSe}=225,702, \mathrm{p}<.001$, in the positive-, negative-, zero-, and no-expectation groups, respectively]. In spite of the strong linear trends, there were significant,

Table 1

Scanning-Time/Distance Correlations

\begin{tabular}{|c|c|c|c|c|c|}
\hline \multirow[b]{2}{*}{ Correlations } & \multicolumn{5}{|c|}{ Experimental Groups } \\
\hline & $\begin{array}{c}\text { Positive } \\
\text { Expectations }\end{array}$ & $\begin{array}{c}\text { Negative } \\
\text { Expectations }\end{array}$ & $\begin{array}{c}\text { Zero } \\
\text { Expectations }\end{array}$ & $\begin{array}{c}\text { No } \\
\text { Expectations } \\
\end{array}$ & $\begin{array}{l}\text { All } \\
\text { Groups }\end{array}$ \\
\hline $\begin{array}{l}\text { Mean } \\
\text { Scanning Times }\end{array}$ & .89 & .58 & .77 & .82 & .84 \\
\hline $\begin{array}{l}\text { Mean for } \\
\text { Individual Ss }\end{array}$ & .54 & .16 & .32 & .30 & .33 \\
\hline $\begin{array}{l}\text { Median for } \\
\text { Individual Ss }\end{array}$ & .53 & .12 & .37 & .26 & .33 \\
\hline $\begin{array}{l}\text { Maximum for } \\
\text { Individual Ss }\end{array}$ & .93 & .80 & .70 & .88 & .93 \\
\hline $\begin{array}{l}\text { Minimum for } \\
\text { Individual Ss }\end{array}$ & -.12 & -.27 & -.15 & -.34 & -.34 \\
\hline $\begin{array}{l}\text { Standard } \\
\text { Deviations }\end{array}$ & .30 & .28 & .26 & .33 & .32 \\
\hline $\begin{array}{l}\text { Number of Reliable } \\
\text { Positive Correlations }\end{array}$ & 14 & 4 & 4 & 6 & 28 \\
\hline
\end{tabular}

Note $-S=$ subject. 
albeit relatively small, departures from linearity in the positive- and negative-expectation groups $[F(19,340)=$ $2.14, \mathrm{MSe}=128,573, \mathrm{p}<.05 ; \mathrm{F}(19,340)=1.95$, MSe $=334,981, \mathrm{p}<.05 ; \mathrm{F}(19,340)=1.30, \mathrm{MSe}=$ $137,000, \mathrm{p}>.10$; and $\mathrm{F}(19,340)=1.57$, MSe $=$ $225,702, \mathrm{p}>.10$, in the positive-, negative-, zero-, and no-expectation groups, respectively]. Scanning times for each of the four groups are depicted in Figure 1.

The scanning rates for the differently instructed conditions were $47 \mathrm{msec} / \mathrm{cm}, 27 \mathrm{msec} / \mathrm{cm}, 24 \mathrm{msec} / \mathrm{cm}$, and $38 \mathrm{msec} / \mathrm{cm}$ for the positive-, negative-, zero-, and noexpectation groups, respectively. The slope of the positive-expectation group approximated the $45 \mathrm{msec} / \mathrm{cm}$ reported by Kosslyn et al. (1978). The slope in the positive-expectation group was steeper than the slopes in the negative- and zero-expectation groups $[F(1,680)=$ $8.25, \mathrm{p}<.005$, and $\mathrm{F}(1,680)=18.88, \mathrm{p}<.001$, respectively]. The slope in the no-expectation group was intermediate to the slopes in the positive- and negativeexpectation groups and not significantly different from either $[F(1,680)=1.92, p>.10$, and $F(1,680)=2.28$, $\mathrm{p}>.10$, respectively]; however, the slope in the noexpectation group was steeper than the slope in the zero- expectation group $[\mathrm{F}(1,680)=5.51, \mathrm{p}<.025]$. The slopes in the negative- and zero-expectation groups were not significantly different $[F(1,680)<1.0]$.

The one-way ANOVA performed on the Fisher Z transformations of individual subjects' correlations indicated significant effects of condition $[\mathrm{F}(3,68)=5.43, \mathrm{MSe}=$ $.16, \mathrm{p}<.005]$. Neuman-Keuls tests revealed that correlations in the negative-, zero-, and no-expectation groups were lower than correlations in the positive-expectation group; no other differences were significant. In addition, the proportion of positive reliable correlations was greater in the positive-expectation group than in the negative-, zero-, and no-expectation groups $\left[\chi^{2} \mathrm{~s}(1, \mathrm{~N}=36)=\right.$ $11.11,11.11$, and 7.20, respectively, ps $<.01]$. Thus, scanning time was significantly related to distance for proportionately fewer subjects in these latter three groups than for subjects instructed to expect a positive scanningtime/distance relationship.

\section{Memory for the Map}

The correlation between interobject distance on the original map and interobject distance on the map drawn from memory served as a measure of the accuracy of

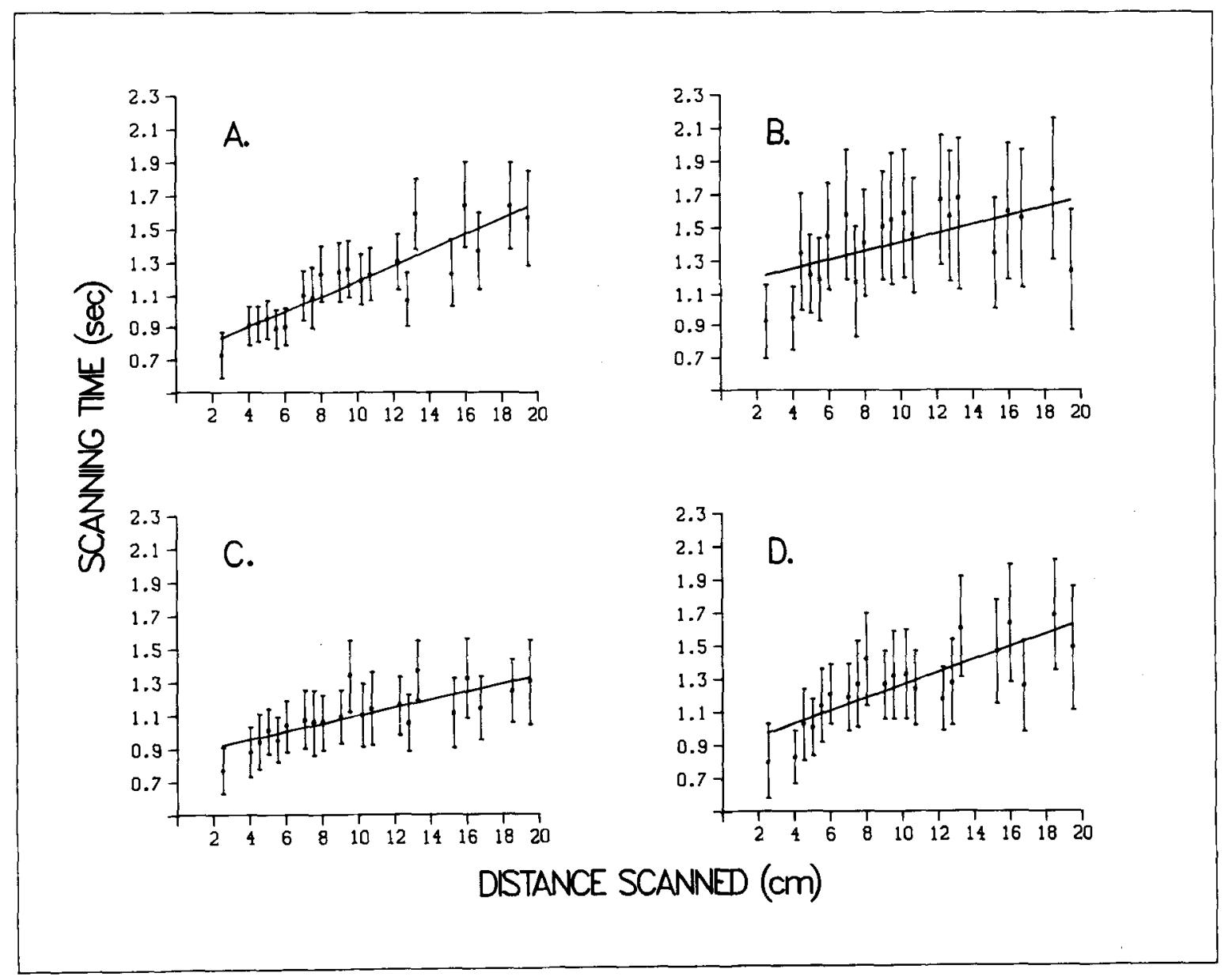

Figure 1. Average scanning times (and standard errors) as a function of distance in the (A) positive-, (B) negative-, (C) zero-, and (D) no-expectation groups. 
recall. These correlations ranged from +.987 to +.999 , with mean and median correlations of +.996 and +.997 , respectively. Interestingly, even with these very high correlations, the one-way ANOVA performed on the Fisher $\mathrm{Z}$ transformations of these correlations indicated a significant effects of condition $[\mathrm{F}(3,67)=3.86$, MSe $=.07, \mathrm{p}<.025]$. Neuman-Keuls tests revealed that reproduction of the map in the negative-expectation group (mean correlation $=+.995$ ) was less accurate than reproduction of the map in the no-expectation group (mean correlation $=+.997$ ). This minute difference did not significantly alter the relationship between scanning time and distance; these correlations were virtually identical whether the initial or the remembered map was used to determine distance between objects. Similarly, the results of statistical analyses were not substantially different when the initial or the remembered map was used to calculate interobject distances.

\section{Practice Effects}

Differences in scanning-time/distance correlations across the four experimental groups were apparently not due to any differential practice effects with repeated trials of scanning. A multiple regression with scanning times regressed on interobject distance on the original map, interobject distance on the drawn map, trial number, condition, and the trial number $\times$ condition interaction indicated that there was a practice effect with scanning times decreasing over trials $[\mathrm{B}=-.09, \mathrm{~F}(1,2965)=4.49$, $\mathrm{p}<.05$ ], but this effect did not differ across conditions $[\mathrm{B}=.02, \mathrm{~F}(1,2965)<1.00]$. There was no overall effect of condition on scanning times $[B=-.02, F(1,2965)$ $<1.00]$.

\section{GENERAL DISCUSSION}

As predicted, subjects' a priori beliefs did alter the scanning-time/distance relationship. When subjects were informed that scanning times would increase with shorter distances, that scanning times would not differ, or that the experimenter had no expectations for their performance, individual subjects generated lower correlations than when they were informed that scanning times would increase with longer distances. In fact, only a minority of subjects in groups other than the positive-expectation group generated significant scanning-time/distance relationships.

For the group results, however, scanning time increased in a linear manner with increasing distance in all groups. In spite of this, instructions (and consequent expectations) affected the strength (the slopes) of the scanning-time/distance functions across subjects. This finding complements the Goldston and Richman (1982) finding that scanningtime/distance slopes vary as a function of self-rated expectancies, and disconfirms Jolicoeur and Kosslyn's (1985) conclusion that subjects' expectations affect only the intercept and not the slope or stength of the scanningtime/distance relationship. These data are therefore con- sistent with Pylyshyn's (1981) assertion that the scanning task is cognitively penetrable.

However, the supposed analog representations of distance and instructional set were not the only factors influencing the scanning-time/distance relationship, as is evidenced by the variability in Table 1 and Figure 1 . Differences in attention, task interpretation, visuomotor coordination, imagery vividness (Finke \& Schmidt, 1978; Harris, 1982), and abilities in different imageryprocessing modules (e.g., LOAD, PUT, REGENERATE, SCAN, PICTURE; Kosslyn et al., 1984) are possible contributors to this variability. The individual variability extends the recent Kosslyn et al. (1984) demonstration of individual differences in a variety of imagery tasks other than the scanning task, and poses problems for the Kosslyn (1981) analog theory which was predicated on the regularity in subjects' imagery performances.

In summary, present results from the mental map scanning task (1) indicate that individual subjects' scanningtime/distance correlations vary as a function of instruction set (and hence, a priori expectations); and (2) reveal a large degree of individual variability in scanningtime/distance correlations. Interactive and/or delimiting influences of semantic and tacit knowledge upon "depictive" imaginal representations, and the causes of individual variability need to be explicated in future revisions of the analog theory.

\section{REFERENCES}

Crowne, D., \& Marlowe, D. (1960). A new scale of social desirability independent of psychopathology. Journal of Consulting Psychology, 34, 349-354

FINke, R., \& PiNkER, S. (1982). Spontaneous imagery scanning in mental extrapolation. Journal of Experimental Psychology: Leaming, Memory, \& Cognition, 8, 142-147.

FinkE, R., \& Pinker, S. (1983). Directional scanning of remembered visual pattems. Journal of Experimental Psychology: Learning, Memory, \& Cognition, 9, 398-410.

FinkE, R., \& SCHMIDT, M. (1978). The qualitative measure of pattern representation in images using orientation-specific color aftereffects. Perception \& Psychophysics, 23, 515-520.

Finke, R., \& SHEPARD, R. (in press). Visual functions in mental imagery. In L. Kaufman \& J. Thomas (Eds.), Handbook of perception and human performance. New York: Wiley.

Goldston, D., \& Richman, C. L. (1982). Mental travel: Demand and individual differences. Paper presented at the annual meeting of the American Psychological Association, Washington, DC.

HARRIS, J. (1982). The VVIQ and imagery-induced McCollough effects: An alternative analysis. Perception \& Psychophysics, 32, 290-292.

INTONS-PETERSON, M. (1983). Imagery paradigms: How vulnerable are they to experimenters' expectations? Journal of Experimental Psychology: Human Perception \& Performance, 9, 394-412.

Jolicoevr, P., \& Kosslyn, S. 1985). Is time to scan visual images due to demand characteristics? Memory \& Cognition, 13, 320-332.

KERR, N., \& NeISSER, U. (1983). Mental images of concealed objects. Journal of Experimental Psychology: Learning, Memory, \& Cognition, 9, 212-221.

Kosslyn, S. (1981). The medium and the message in mental imagery: A theory. Psychological Review, 88, 46-66.

Kosslyn, S., BAlL, T., \& ReIsER, B. (1978). Visual images preserve metric spatial information: Evidence from studies of image scanning. Journal of Experimental Psychology: Human Perception \& Performance, 4, 47-60. 
Kosslyn, S., BrunN, J., CAve, K., \& Wallach, R. (1984). Individual differences in mental imagery ability: A computational analysis. Cognition, 18, 195-243.

Kosslyn, S., Pinker, S., Smith, G., \& Shwartz, S. (1979). On the demystification of mental imagery. The Behavioral \& Brain Sciences, 2, 535-581.

Mitchell, D., \& Richman, C. L. (1980). Confirmed reservations: Mental travel. Journal of Experimental Psychology: Human Perception \& Performance, 6, 58-66.

Pinker, S., ChOATE, P., \& Finke, R. (1984). Mental extrapolation in patterns constructed from memory. Memory \& Cognition, 12, 207-218.

PYLYSHYN, Z. (1981). The imagery debate: Analogue media versus tacit knowledge. Psychological Review, 88, 16-45.

Richman, C. L., MitchelL, D., \& RezniCK, J. (1979). Mental travel: Some reservations. Journal of Experimental Psychology: Human Perception \& Performance, 5, 13-18.

\section{NOTE}

1. Experiments by Finke and Pinker (1982, 1983; Pinker, Choate, \& Finke, 1984) in which subjects recalled visual information presented seconds earlier, but in which subjects were never explicitly instructed to use imagery, would seem to rule out subjects' expectations as an explanation for imagery-scanning performance. However, it is not clear whether these experiments were tapping the same processes as experiments in which subjects are instructed to manipulate intentionally memorized images for prolonged periods of time.

(Manuscript received December 11, 1984; revision accepted for publication June 15, 1985.) 